\title{
SYNTHESIS OF MODULAR-STRUCTURED SYSTEMS FOR AUTOMATIZATION OF DECISION-MAKING PROCESSES IN TRANSPORT LOGISTICS
}

\author{
Yuriy P. Kondratenko ${ }^{1)}$, Sylvia B. Encheva ${ }^{2)}$, levgen V. Sidenko ${ }^{1)}$ \\ 1) Petro Mohyla Black Sea State University, 68th Desantnykiv Str. 10, Mykolaiv 54003 Ukraine, \\ y_kondratenko@rambler.ru, emoty@mail.ru \\ ${ }^{2)}$ Stord/Haugesund University College, Klingenbergvegen 8, N-5414 Stord, Norway, silvia.encheva@hsh.no
}

\begin{abstract}
The ranging analysis of transport logistics problems and decision-making methods were held in the paper. The problems, which are represented as subsystems of DSS (Decision Support System) module type, were considered. One of which, in particular, evaluation of the quality of transport services to select cargo shipping company, was considered in details.
\end{abstract}

Keywords: transport logistics, DSS, fuzzy logic, knowledge base, services quality.

\section{INTRODUCTION}

Formation and organization of cargo shipping chains work is associated with intense and rapid exchange of information between participants of transport process [1]. Transport companies need to select kind and type of vehicles and organize transportations providing the required level of shipping quality, which determines the profit of company, its image, and competitiveness [2]. To increase the efficiency of cargo transportation the significant role is assigned to informational technologies and software tools that allow accompanying the stages of transport logistics on the new intellectual level [2].

\section{PROBLEM STATEMENT}

Customers of transport services often are not satisfied with the quality of services, as there take place violations of delivery terms, spoiling and loosing cargo [1]. This is due to the complexity of cooperation process of large number of forwarders, carriers and logistic companies. This raises a difficulty of constructing rational routes of cargo transportation, absence of universal program systems that accompany processes of cargo transportation in real time [2]. The important aspect of modern transport logistics is to ensure continuity of controlled processes in transport nodes, where while cargo passing nets of different transport agencies are crossing, an exchange of information between different nets takes place. It concerns, for example, transshipment points (ports, railway stations, etc.), and organization of uninterrupted mixed transportations $[3,4]$.

Development of decision-making support system (DSS) will allow resolving problem issues of coordination of interaction between different objects-participants of cargo transportation process, selecting optimal routes and others $[5,6]$.

Solving complex of problems associated with the organization of cargos movement implies a previous classification of transport logistics problems [5]. It is necessary to increase efficiency of decision making. Herein it is reasonable to define methods that are the most effective to use in the process of solving determined tasks.

The analysis and research of transport logistics tasks $[5,6,7]$ allows to outline the main ones that are presented in the form of DSS subsystems module type in Fig.1

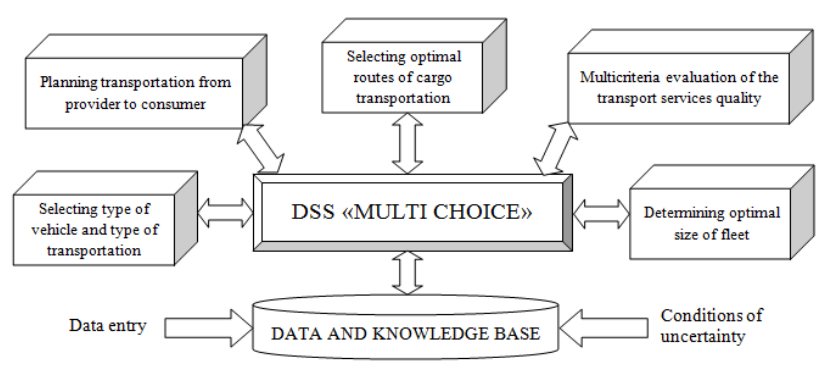

Fig. 1 - Module structure of DSS “MULTI CHOICE”

The purpose of this paper is developing approaches of structural and algorithmic 
organization of DSS modules to solve transport logistics tasks, in particular, to estimate the quality of transport services.

\section{MODULES' CHARACTERISCTICS OF DSS "MULTI CHOICE"}

DSS module (Fig. 1) to select type of vehicle and type of transportation.

The task of selecting the type of vehicle is solved in conjunction with other logistics tasks, in particular, creating and maintaining optimal stocks level, choosing type of packing and others. The basis of transport selection, optimal for a specific transportation, is information about features of different types of vehicles. Currently there is a problem of a large number of advantages and disadvantages for each type of vehicle [1].

Transport logistics identifies five types of transport (railway, road, air, marine and pipeline) [1, $2,3]$. Herein selection of optimal transport depends on conditions of transportation of a particular company.

When selecting railway transport the main advantages are transportation of large consignment of goods under any climatic conditions, their regularity, low cost of cargo delivery. While low speed and impossibility of delivery to remote locations refer to serious disadvantages [2].

The main advantages of road transport are high mobility of vehicle, delivery directly to the place of destination, sending cargos over short distances. Herein the urgency of loading off cargo, high cost of cargo transportation and relatively low cargo capacity of road vehicles imposes similar restrictions on the process of transportation [2].

When choosing a type of marine and air transport should be noted dependence on navigation and weather conditions, and also the low frequency [4].

The analysis [1-4] of pro and cons of each type of transport means allows to identify the main criteria of selecting the optimal type of transport. These include (Fig. 2): the possibility of cargo delivering to any point in the territory (K1), timeliness of delivery (K2), security of cargo (K3), frequency of cargo transportation (K4), transport expenses (K5), cargo capacity (K6), ability to transport different types of cargo (K7), independence from climatic conditions (K8), overcoming large distances (K9), urgency of loading off (K10). As alternative variants there are main types of transport (Fig. 2): road (A1), railway (A2), marine (A3), air (A4) and pipeline (A5).

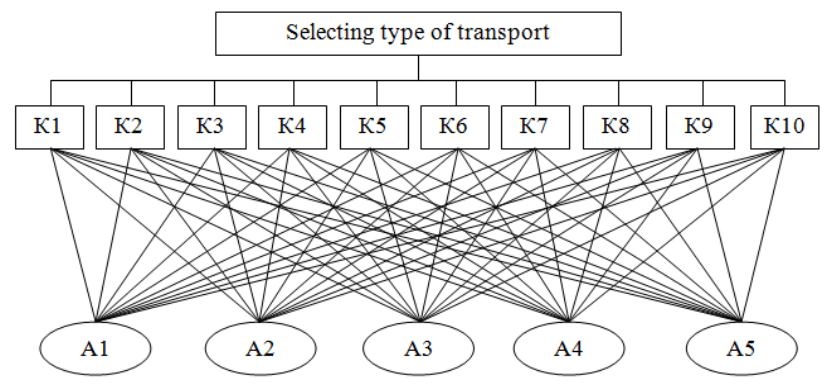

Fig. 2 - The structure of DSS module

The task of selecting the optimal type of transport is reduced to solution of the decision tree (Fig. 2) using method of Analytic Hierarchy Process. For a specific DM the priority of criteria with respect to main goal may vary. It depends on conditions of uncertainty in the transportation process (time and distance constraints, weather conditions) and strategies of transport companies [8].

The process of cargo delivery using one type of transport is typical for unimodal type of transportation [9]. However, to increase the efficiency of shipping transport companies combine advantages of different types of transport, while avoiding disadvantages. Such type of transportation is called mixed or multimodal. The problem of corresponding cargo transportation lies in complexity of actions coordination of different participants of the cargo transportation process. Herein the cost and time of transportation increase. Selection of cargo transportation type in each individual case is determined by cost of delivery, speed of order execution and other factors. The analysis of literature and scientific researches shows that usage of the critical path method allows to determine optimal combination of several transport types $[9,10]$. Thus at the final stage is planning to get optimal combination of logistics intermediaries, which take part in the cargo transportation process.

DSS module (Fig. 1) to select optimal routes of cargo transportation.

Selection of optimal transportation routes depends on specifics of the cargo, its size and purpose. Particular difficulty presents selection of route for large size and dangerous cargos [1].

In the result of analysis and comparison of possible alternative routes DM selects the optimal variant for the specific criteria. Among them may be: minimum transportation path length, time of transportation, transport expenses, cargo residues when implementing routes and others [5].

Investigation and analysis of problems of selecting the optimal transportation routes allow to outline main tasks of combinatorial optimization (class NP-hard problems), solving of which leads to 
solution of corresponding problem. To such tasks correspond: travelling salesman problem (TSP), vehicle routing program (VRP) with restrictions on cargo capacity (CVRP) and "time windows" (WRPTW), problem of the pack (KP). Thus finding the optimal route requires full search of all possible alternative decisions. There is a problem of increasing computational expenses by increase of the vector of input information dimension [11].

Let's consider the example of the deterministic task of planning routes for 33 nodes $(N=33)$, when all initial information is known (coordinates of diversified transport system nodes and volume of orders in the form of distinct values)

Coordinates of nodes $X_{i}, Y_{i}, i \in\{1,2, \ldots, N\}$, where cargo consumers are, are presented in Table 1, cargo capacity of transportation unit $D_{\max }=5$ tons, order $Q_{i}, i \in\{1,2, \ldots, N\}$ in nodes are presented in Table 2 .

Table 1. Coordinates of diversified transport system nodes

\begin{tabular}{|c|c|c|c|c|c|c|c|c|}
\hline $\begin{array}{c}\text { № } \\
\text { node }\end{array}$ & $X_{i}$ & $Y_{i}$ & $\begin{array}{c}\text { № } \\
\text { node }\end{array}$ & $X_{i}$ & $Y_{i}$ & $\begin{array}{c}\text { № } \\
\text { node }\end{array}$ & $X_{i}$ & $Y_{i}$ \\
\hline $\mathbf{1}$ & 26 & 59 & $\mathbf{1 2}$ & 66 & 14 & $\mathbf{2 3}$ & 31 & 76 \\
\hline $\mathbf{2}$ & 40 & 66 & $\mathbf{1 3}$ & 44 & 13 & $\mathbf{2 4}$ & 22 & 53 \\
\hline $\mathbf{3}$ & 55 & 65 & $\mathbf{1 4}$ & 26 & 13 & $\mathbf{2 5}$ & 26 & 29 \\
\hline $\mathbf{4}$ & 35 & 51 & $\mathbf{1 5}$ & 11 & 28 & $\mathbf{2 6}$ & 50 & 40 \\
\hline $\mathbf{5}$ & 62 & 35 & $\mathbf{1 6}$ & 7 & 43 & $\mathbf{2 7}$ & 60 & 40 \\
\hline $\mathbf{6}$ & 62 & 57 & $\mathbf{1 7}$ & 17 & 64 & $\mathbf{2 8}$ & 60 & 15 \\
\hline $\mathbf{7}$ & 62 & 24 & $\mathbf{1 8}$ & 41 & 46 & $\mathbf{2 9}$ & 47 & 66 \\
\hline $\mathbf{8}$ & 21 & 36 & $\mathbf{1 9}$ & 55 & 34 & $\mathbf{3 0}$ & 30 & 60 \\
\hline $\mathbf{9}$ & 33 & 44 & $\mathbf{2 0}$ & 35 & 16 & $\mathbf{3 1}$ & 30 & 50 \\
\hline $\mathbf{1 0}$ & 9 & 56 & $\mathbf{2 1}$ & 52 & 26 & $\mathbf{3 2}$ & 12 & 17 \\
\hline $\mathbf{1 1}$ & 62 & 48 & $\mathbf{2 2}$ & 43 & 26 & $\mathbf{3 3}$ & 15 & 14 \\
\hline$X_{0}=40, Y_{0}=40-$ coordinates of base node (\#=0), where \\
warehouse complex and transportation company are situated \\
\hline
\end{tabular}

Table 2. Cargo ordering in each set of nodes

\begin{tabular}{|c|c|c|c|c|c|}
\hline node $\#$ & $Q_{i}$ & node $\#$ & $Q_{i}$ & node \# & $Q_{i}$ \\
\hline $\mathbf{1}$ & 0,8681 & $\mathbf{1 2}$ & 0,8791 & $\mathbf{2 3}$ & 0,3472 \\
\hline $\mathbf{2}$ & 0,6997 & $\mathbf{1 3}$ & 0,4565 & $\mathbf{2 4}$ & 0,1072 \\
\hline $\mathbf{3}$ & 0,7929 & $\mathbf{1 4}$ & 0,1406 & $\mathbf{2 5}$ & 0,5455 \\
\hline $\mathbf{4}$ & 0,8111 & $\mathbf{1 5}$ & 0,0981 & $\mathbf{2 6}$ & 0,7128 \\
\hline $\mathbf{5}$ & 0,1842 & $\mathbf{1 6}$ & 0,5704 & $\mathbf{2 7}$ & 0,7950 \\
\hline $\mathbf{6}$ & 0,2531 & $\mathbf{1 7}$ & 0,1034 & $\mathbf{2 8}$ & 0,6341 \\
\hline $\mathbf{7}$ & 0,9053 & $\mathbf{1 8}$ & 0,2872 & $\mathbf{2 9}$ & 1,0205 \\
\hline $\mathbf{8}$ & 0,4809 & $\mathbf{1 9}$ & 0,3286 & $\mathbf{3 0}$ & 0,3373 \\
\hline $\mathbf{9}$ & 0,8336 & $\mathbf{2 0}$ & 0,2594 & $\mathbf{3 1}$ & 0,6244 \\
\hline $\mathbf{1 0}$ & 0,5102 & $\mathbf{2 1}$ & 0,5658 & $\mathbf{3 2}$ & 0,0400 \\
\hline $\mathbf{1 1}$ & 0,6735 & $\mathbf{2 2}$ & 0,7832 & $\mathbf{3 3}$ & 0,2592 \\
\hline
\end{tabular}

Using data (Table 1,2) let's form routes of vehicles with cargo capacity $D_{\max }$ on the basis of results of saving-algorithm for total orders (Fig. 3).

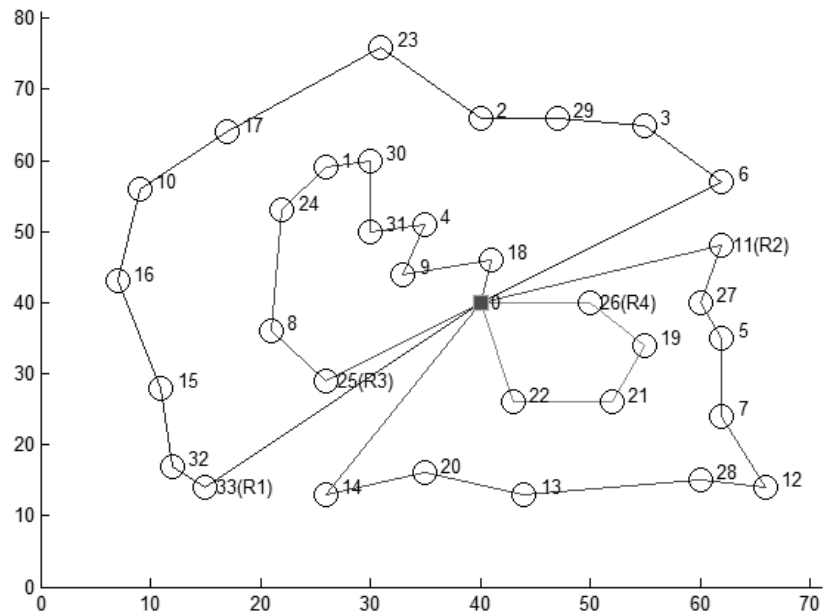

Fig. 3 - Routes of transportation

According to Hamiltonian cycles, formation of which is based on saving-algorithm, there are designated $S=4$ routes $R_{i}, i \in\{1,2, \ldots, S\}$ of different length and structure (Fig. 3). It depends on cargo capacity of vehicles and volume of orders in nodes. For shipping of total orders 4 transportation units are needed for 4 routes accordingly. In the Table 3 there are presented length of each route $L_{r}, r \in\{1,2, \ldots, R\}$, the amount of carried cargo $Q_{r}, r \in\{1,2, \ldots, R\}$ and residual amount of cargo $\Delta D_{\gamma}$. Herein there are determined the total length of all routes $L_{\Sigma}=448,3 \mathrm{~km}$, the volume of orders in nodes $Q_{\Sigma}=16,91$ tons and performance indicator of vehicles workload $E=0,85$ by equation (1).

$$
E=\frac{1}{R} \sum_{\gamma=1}^{R}\left(1-\frac{\Delta D_{\gamma}}{D_{\max }}\right)
$$

Table 3. Routes characteristics

\begin{tabular}{|c|l|c|c|c|}
\hline $\mathbf{R}$ & \multicolumn{1}{|c|}{ Route structure } & $L_{r}$ & $Q_{r}$ & $\Delta D_{\gamma}$ \\
\hline 1 & $\begin{array}{l}0-33-32-16-16-10-17-23-2-29- \\
3-6-0\end{array}$ & 176,74 & 4,69 & 0,31 \\
\hline 2 & $0-11-27-5-7-12-28-13-20-14-0$ & 130,41 & 4,93 & 0,07 \\
\hline 3 & $0-25-8-24-1-30-31-4-9-18-0$ & 91,48 & 4,90 & 0,10 \\
\hline 4 & $0-26-19-21-22-0$ & 49,67 & 2,39 & 2,61 \\
\hline
\end{tabular}

Depending on conditions of uncertainty (volume of orders in nodes) and cargo capacity of vehicles, the amount and the structure of routes can vary.

The task of planning transportation routes becomes more complicated if orders in nodes are represented as fuzzy numbers, for example, triangular shape of membership function [14]. Usage of DSS module (Fig. 1) to select optimal routes of cargo transportation also is designed for solving problems of corresponding complexity. 
DSS module for planning transportation from suppliers to consumers (Fig. 1).

Analysis of literature $[1,2,14]$ shows that one of the approaches to solving tasks of cargo transportation planning is bringing it to transportation task of Monge-Kantorovich. It is a mathematical problem of linear programming to find optimal plan to separate homogeneous objects from suppliers (warehouses) to consumers. Herein expenses on transportation should be minimal.

At present we know several methods (algorithms) of solving transportation problem of linear programming. These include: methods of northwest corner, minimum value, Vogel (to get initial plan), method of potentials to improve key plan and to get the best variant of cargo transferring. In many transportation companies the problem of planning routes of cargo delivering and passengers is solved with the help of the distribution method, the deltamethod, network methods, etc. But such problems are often compounded by varied conditions and restrictions, in particular, the necessity of cargo delivering in minimum time, the availability of cargo and demand for it are not balanced, etc. [15]. One of the disadvantages of transport problem is that the model of cargo transportation does not take into account the heterogeneity of freight cargo and vehicles. Solution of this problem is achieved by means of considering multiindex (three-planar T-3P and three-axial T-3A) transportation tasks [16]. Solution of such class of problems allows to get optimal plan of transportation of diverse cargo by different types of vehicles.

Let's consider the example of apple transportation planning from 3 companies $\left\{P_{1}, P_{2}, P_{3}\right\}$, which grow them, to 6 customers $\left\{K_{1}, K_{2}, \ldots, K_{6}\right\}$. Moreover, each of them should get the appropriate amount of products. It is necessary to develop such transportation plan, when total expenses on its realization are minimal. Scheme of transport links between suppliers and customers are presented in Fig. 4.

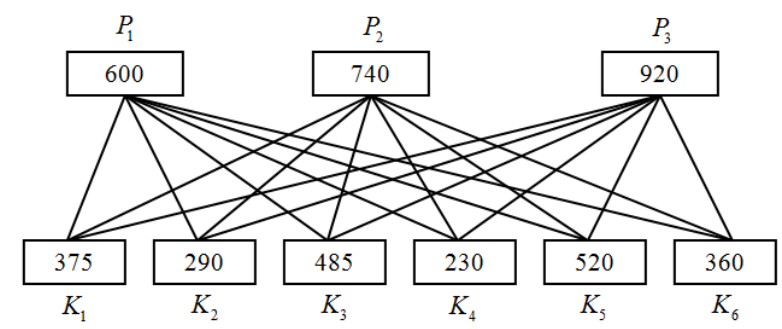

Fig. 4 - Scheme of transport links

In table 4 there are represented accurate values of transportation expenses $c_{i j}, i \in\{1,2, \ldots, P\}, j \in\{1,2, \ldots, K\}$ on transportation of product unit from suppliers
$P_{i}, i \in\{1,2, \ldots, P\}$ to customers $K_{i}, i \in\{1,2, \ldots, K\}$

Table 4. Matrix of transportation expenses

\begin{tabular}{|c|c|c|c|c|c|c|}
\hline & $\boldsymbol{K}_{\mathbf{1}}$ & $\boldsymbol{K}_{\mathbf{2}}$ & $\boldsymbol{K}_{\mathbf{3}}$ & $\boldsymbol{K}_{\mathbf{4}}$ & $\boldsymbol{K}_{\mathbf{5}}$ & $\boldsymbol{K}_{\mathbf{6}}$ \\
\hline $\boldsymbol{P}_{\mathbf{1}}$ & 4 & 1 & 2 & 7 & 8 & 5 \\
\hline $\boldsymbol{P}_{\mathbf{2}}$ & 7 & 5 & 3 & 4 & 6 & 8 \\
\hline $\boldsymbol{P}_{\mathbf{3}}$ & 8 & 4 & 6 & 2 & 5 & 10 \\
\hline
\end{tabular}

With the help of linear programming methods we find initial plan, and then improve it to optimum, for example, ss-method. We get the decision tree (Fig. 5 ), in the root of which there is an alternative decision (plan) $E_{1}^{1}$ with a value of objective function $Z_{1}=10545$ uah. Further the initial plan improves till on the next stage the value of objective function is not changing.

This means that the optimal plan found.
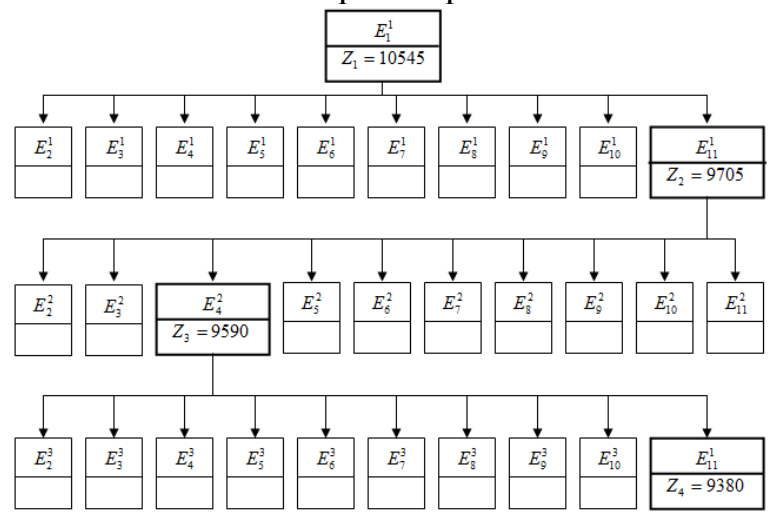

Fig. 5 - Decision tree for transportation planning

For considered example the transportation plan, that meets alternative decision $E_{11}^{3}$ with the value of the objective function $Z_{3}=9380$ uah., is optimal (Table 5).

Table 5. Optimal transportation plan

\begin{tabular}{|c|c|c|c|c|c|c|c|}
\hline & $\boldsymbol{K}_{\mathbf{1}}$ & $\boldsymbol{K}_{\mathbf{2}}$ & $\boldsymbol{K}_{\mathbf{3}}$ & $\boldsymbol{K}_{\mathbf{4}}$ & $\boldsymbol{K}_{\mathbf{5}}$ & $\boldsymbol{K}_{\mathbf{6}}$ & $\boldsymbol{O}$ Offer \\
\hline $\boldsymbol{P}_{\mathbf{1}}$ & 375 & 120 & & & & 105 & $\mathbf{6 0 0}$ \\
\hline $\boldsymbol{P}_{\mathbf{2}}$ & & & 485 & & & 255 & $\mathbf{7 4 0}$ \\
\hline $\boldsymbol{P}_{3}$ & & 170 & & 230 & 520 & & $\mathbf{9 2 0}$ \\
\hline Demand & $\mathbf{3 7 5}$ & $\mathbf{2 9 0}$ & $\mathbf{4 8 5}$ & $\mathbf{2 3 0}$ & $\mathbf{5 2 0}$ & $\mathbf{3 6 0}$ & $\mathbf{2 2 6 0}$ \\
\hline
\end{tabular}

One of the problems of cargo transportation planning is unpredictability of the input data changes, where take place orders and expenses on transportation in the form of fuzzy numbers. Algorithm of the ss-method allows to get over to solving of problem of transportation planning in the assumption that the costs are fuzzy [13]. For convenience in performing corresponding calculations and easiness of getting fuzzy data we will fuzzy numbers of triangular shape (FNT) that, for example, correspond to values of expenses $q_{1}$ for external conditions $F_{1}, q_{2}$ for external 
conditions $F_{2}$ and $q_{3}$ external conditions $F_{3}$. In Fig. 6 there is represented FNT $\underset{\sim}{q}=\left(q_{1}, q_{2}, q_{3}\right)$ that characterize expenses on cargo unit transportation.

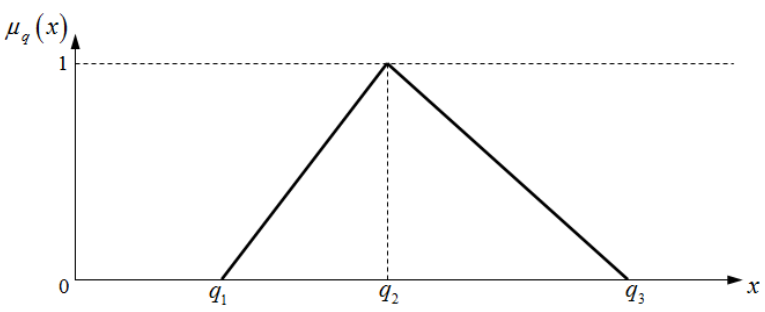

Fig. 6 - Expenses on cargo unit transportation

To use ss-method it is necessary to do operations of addition, subtraction and comparison of FNT [12]. Comparison can be made in various ways, one of which is based on identifying deviations according to formula (2).

$$
\xi(\underset{\sim}{A}, 0)=\frac{a_{1}+2 a_{2}+a_{3}}{2}, a_{1}, a_{2}, a_{3} \in R
$$

Of the two alternative decisions is chosen that, which deviation is lower. For example, for the alternative decision (transportation plan) $E_{3}^{1}$ with value of performance function in form of FNT $Z_{3}^{1}=(1010,1560,2130)$, deviation will be $\xi(Z, 0)=3130$. Thus for the alternative decision $E_{8}^{1}$ with value of function $Z_{3}^{1}=(930,1580,2020)$ in the form of FTN, deviation is $\xi(Z, 0)=3070$. In such case the alternative decision $E_{8}^{1}$ is better than decision $E_{3}^{1}$.

DSS module to select the optimal size of fleet (Fig. 1).

To determine the optimal size of the fleet it is necessary to consider cost metrics for formation of quantitative assessments $e_{i j}, i=1, \ldots, M_{\Sigma}, j=1, \ldots, 3$ of alternative variants of decisions $E_{i}$ for different programs of general cargo transportation capacity $F_{1}, F_{2}, F_{3}$.

The general amount of alternative decisions $M_{\Sigma}$ in matrix of decisions is determined as follows:

$$
\begin{aligned}
& E_{1}=F_{1} \operatorname{div} D_{\text {max }} ; \\
& E_{R_{\max }}=F_{5} \operatorname{div} D_{\text {max }}+2 \geq R_{\text {max }} \\
& M_{\Sigma}=E_{R_{\max }}-E_{1}+1
\end{aligned}
$$

The elements $e_{i j}$ of matrix solution $\left\|e_{i j}\right\|$ are computed by the following algorithms:
- in case of chartering additional vehicles;

- in case of simple part of vehicles.

In the formed matrix of alternative decisions that correspond to the number of vehicles on criteria of decision making the best variant is chosen.

Let's consider one of the problems of this DSS module, in particular, the problem of finding the optimal number of vehicles with minimizing the cost of cargo transportation from supplier to consumer, involving transport terminals (warehouses) [1].

In each warehouse there is a known amount of cargo that needs to be transported from supplier to consumer by defined routes, each of which runs at different time of the day, that's why the amount of goods that needs to be loaded off from transport terminals will also vary [3].

Transportation costs for cargo shipping on each of the routes differ between each other as they include costs of fuel, shipping services, costs associated with keeping cargo in warehouses, freight costs and others [1].

Finding the optimal number of vehicles comes down to solving problems of linear programming with constraints on the cargo volume in warehouses of each route [14].

The usage of graphical method for solution of this problem is limited by the capabilities and easiness of finding the optimal decision. This is due to the use of only two or three variables in performance function (the solution is achieved by finding the optimal decision in two-dimensional and three-dimensional space of constraints). For solving such class of transport logistics problems it is appropriate to use the method of directed enumeration. This method allows to find the optimal decision by the performance function considering all restrictions. Thus for finding the decision they use Newton's method or the method of conjugate gradients $[14,17]$.

DSS module to estimate the quality of transport services (Fig. 1).

Let's consider in more details the principles of structural and algorithmic organization of DSS module by the example of subsystem of transport services quality evaluation (cargo delivering).

\section{STRUCTURAL ORGANIZATION OF DSS MODULE FOR TRANSPORT SERVICES QUALITY EVALUATION}

Analysis of literature [6,7] shows that among input parameters, that impact on transport services quality evaluation, there can be determined 19 the most important ones [18]. Let's consider by the example the structural organization of DSS module for evaluation of cargo delivering quality with 11 indicators $(N=11)$, among which there are: $x_{1}-$ 
custom costs; $x_{2}-$ costs related to possible situations on the road; $x_{3}-$ costs on transportation; $x_{4}$ - reliability of information about the cargo movement; $x_{5}$ - timeliness of giving information; $x_{6}$ - risk during transportation; $x_{7}$ - preservation by amount of cargo; $x_{8}$ - preservation by quality $o$ cargo; $x_{9}$ - timeliness of delivery; $x_{10}$ - possibility of cargo delivering to any place of territory; $x_{11}-$ readiness for delivery.

Output signal is the transport services quality evaluation $(y)$.

Before the beginning of formation process of fuzzy rules database it is important to determine the number and the type of linguistic terms (LT) for evaluation of input and output parameters. To evaluate input coordinates $\left\{x_{1}, x_{2}, \ldots, x_{11}\right\}$ of DSS module 3 LT were elected (L - "low", M "medium", $\mathrm{H}$ - "high"), for output variable - 5 (L "low", LM - "lower the medium", M - "medium", $\mathrm{MH}$ - "higher the medium", H - "high") with triangular shape of membership function.

In the process of DSS development on the basis of fuzzy logical derivation there is a possibility of sharp growth of fuzzy rules bases dimension. Herein there raises a complexity of structure formation and fuzzy rules synthesis. It is due to large dimension of input parameters vector, number and type of corresponding linguistic terms (LT). In such case it is hard for expert to describe cause-effect relationships with the help of fuzzy rules as in human memory can simultaneously store $7 \pm 2$ concepts-features [19].

Here is a structure of fuzzy rule of the productive type.

$$
\begin{aligned}
& \operatorname{IF}\left(x_{1}=I T_{1}^{j}\right) \text { AND }\left(x_{2}=I T_{2}^{j}\right) \text { AND ... } \\
& \operatorname{AND}\left(x_{i}=I T_{i}^{j}\right) \text { AND ... AND }\left(x_{n}=I T_{n}^{j}\right) \\
& \operatorname{THEN~}\left(y=O T^{j}\right),
\end{aligned}
$$

where $I T_{i}^{j}$ is linguistic term $j$ rule for evaluation of $i$ input signal $x_{i}, i=1, \ldots, N$;

$O T^{j}$ is linguistic term $j$ rule for evaluation of output signal $y$.

With such structural organization of rules the sensitivity of DSS towards changes of input coordinates $x_{i}, i=1, \ldots, N(N=11)$ decreases. It is related with complexity of formation of all possible dependences between system parameters.
The structure of DSS module (Fig. 7) is developed so that some inputs of each subsystem do not exceed five. It allows to reduce the number of fuzzy knowledge bases, thus improve the sensitivity of the system towards input variables (factors) actions. Herein it is necessary to conduct structuring of input variables only by common properties that serve as main (important) in frames of subsystem [20]. It I advisable to combine input coordinates in the following groups: $y_{1}=f_{1}\left(x_{1}, x_{2}, x_{3}\right), y_{2}=f_{2}\left(x_{4}, x_{5}\right)$, $y_{3}=f_{3}\left(x_{7}, x_{8}\right), \quad y_{4}=f_{4}\left(x_{9}, x_{10}, x_{11}\right), \quad y_{5}=f_{5}\left(x_{6}, y_{2}\right)$, $y_{6}=f_{6}\left(y_{2}, y_{5}\right), \quad y=f_{7}\left(y_{1}, y_{4}, y_{6}\right)$. Where $y_{i}, i=1, \ldots, 6$ are intermediate variables of DSS module, including: $y_{1}-$ cost of transportation; $y_{2}-$ the level of informativeness o cargo delivery; $y_{3}$ - safety of cargo; $y_{4}$ - image of subjects-participants of cargo transportation; $y_{5}$ - reliability of delivery system; $y_{6}-$ level of cargo transportation.

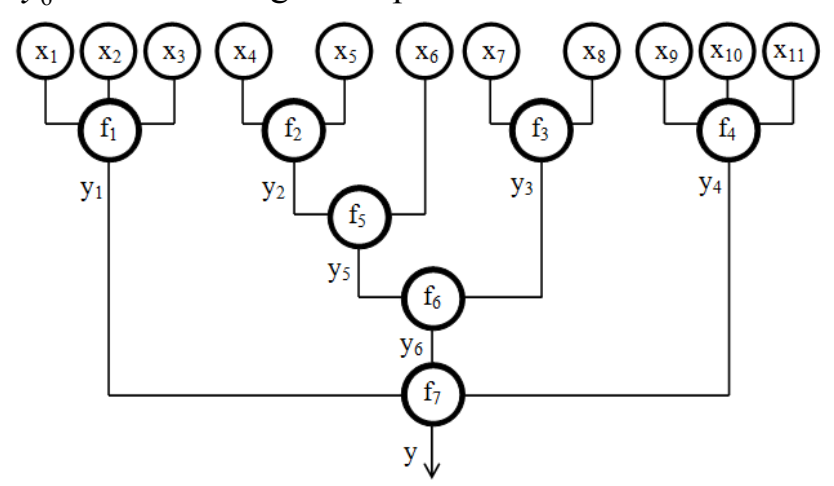

Fig. 7 - The structure of DSS module to evaluate transport services quality

In constructing fuzzy knowledge bases for DSS module (Fig. 7) there are used 3 LT with triangular shape of membership function that are presented for variables $\left\{x_{1}, x_{2}, \ldots, x_{11}, y_{2}, y_{3}, y_{5}, y_{6}\right\}$ in Fig. 8, for variables $\left\{y_{1}, y_{4}, y\right\}-5$ LT in Fig. 9 .

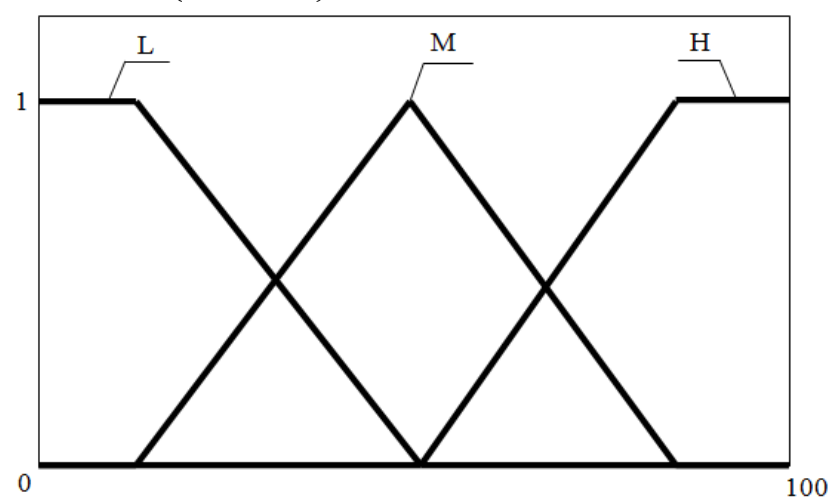

Fig. 8 - linguistic terms of coordinates

$$
\left\{x_{1}, x_{2}, \ldots, x_{11}, y_{2}, y_{3}, y_{5}, y_{6}\right\}
$$


Number of linguistic terms can be changed before the creation of the rule databases [21].

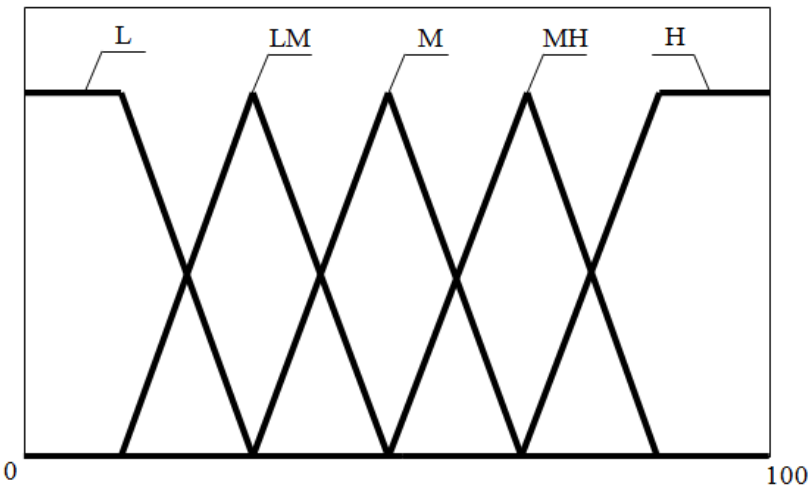

Fig. 9 - linguistic terms of coordinates $\left\{y_{1}, y_{4}, y\right\}$

Selective set $\{1,3,6,10,13,14,15,17,22,25,27\}$ of rules for the first homogeneous subsystem $y_{1}=f_{1}\left(x_{1}, x_{2}, x_{3}\right)$ can be presented as follows:

R1: IF $x_{1}=L$ AND $x_{2}=L$ AND $x_{3}=L$ THEN $y_{1}=L$,

R3: IF $x_{1}=L$ AND $x_{2}=L$ AND $x_{3}=H$ THEN $y_{1}=L M$,

R6: IF $x_{1}=L$ AND $x_{2}=M$ AND $x_{3}=H$ THEN $y_{1}=M$,

R10: IF $x_{1}=M$ AND $x_{2}=L$ AND $x_{3}=L$ THEN $y_{1}=L$,

R13: IF $x_{1}=M$ AND $x_{2}=M$ AND $x_{3}=L$ THEN $y_{1}=L M$,

R14: IF $x_{1}=M$ AND $x_{2}=M$ AND $x_{3}=M$ THEN $y_{1}=M$,

R15: IF $x_{1}=M$ AND $x_{2}=M$ AND $x_{3}=H$ THEN $y_{1}=M H$,

R17: IF $x_{1}=M$ AND $x_{2}=H$ AND $x_{3}=M$ THEN $y_{1}=M$,

R22: $\mathrm{IF} x_{1}=H$ AND $x_{2}=M$ AND $x_{3}=L$ THEN $y_{1}=M$,

R25: IF $x_{1}=H$ AND $x_{2}=H$ AND $x_{3}=L$ THEN $y_{1}=M H$,

R27: IF $x_{1}=H$ AND $x_{2}=H$ AND $x_{3}=H$ THEN $y_{1}=H$.

The structure of the fifth $y_{5}=f_{5}\left(x_{6}, y_{2}\right)$ rules database (heterogeneous type) and the second $y_{2}=f_{2}\left(x_{4}, x_{5}\right)$ (homogeneous type) are presented in Table 6 .

Table 6. Rules database of fifth and second subsystems

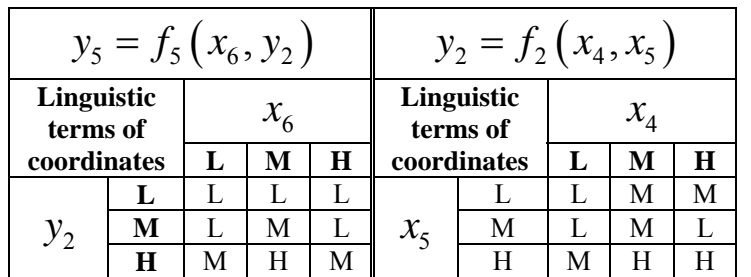

In Fig. 10 there is shown a characteristic surface for the first rules database of the first fuzzy subsystem $y_{1}=f_{1}\left(x_{1}, x_{2}, x_{3}\right)$.

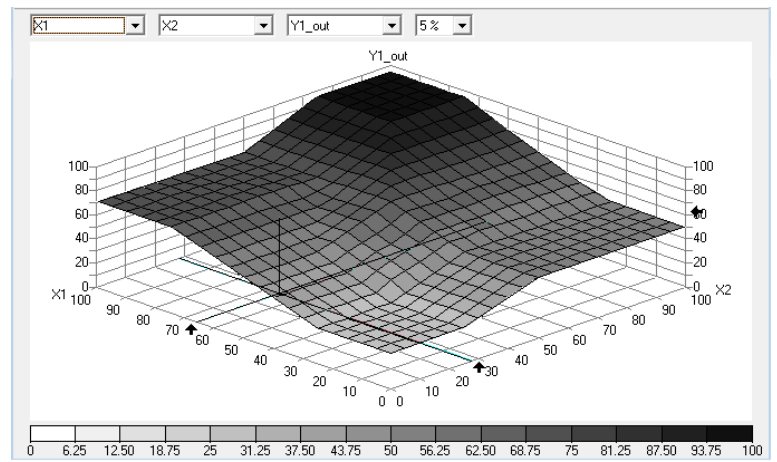

Fig. 10 - Characteristic surface of the first subsystem for the components $\left(x_{1}, x_{2}\right)$

There are several software products that allow to develop DSS on the basis of fuzzy logical derivation. Very famous is the software package MatLab, which includes tools "fuzzy" for development of such class of systems. Also there is an environment FuzzyTECH, which does not become such popular as MatLab, although in some respects it has higher possibilities to develop fuzzy DSS, neural networks and neuro-fuzzy system of forecasting.

\section{SYNTHESIS OF PROJECT AND PROGRAM REALIZATION OF DSS MODULE}

After describing the fuzzy system and developing the fuzzy rules database, the synthesis of fuzzy DSS module is done in the environment of FuzzyTECH. Any system of fuzzy derivation in program environment FuzzyTECH is presented as a separate project [22]. In Fig. 11 there is presented the project of DSS module for evaluation of transportation services quality.

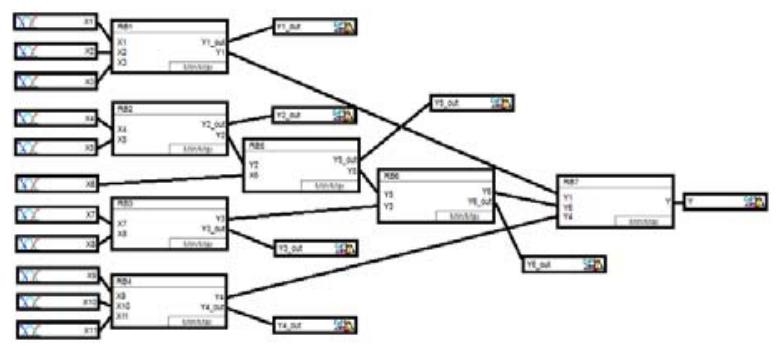

Fig. 11 - The project of DSS module for evaluation of transportation services quality

\section{MODELING RESULTS}

Simulation results of the DSS module to estimate the quality of transport services (Fig. 7) at different alternative variants (I, II, III, IV, V) of the input data are presented in the Table 7 and Table 8. 
Table 7. Alternative variants of the input data

\begin{tabular}{|c|l|l|l|l|l|l|l|l|l|l|l|}
\hline & $\mathrm{X}_{1}$ & $\mathrm{X}_{2}$ & $\mathrm{X}_{3}$ & $\mathrm{X}_{4}$ & $\mathrm{X}_{5}$ & $\mathrm{X}_{6}$ & $\mathrm{X}_{7}$ & $\mathrm{X}_{8}$ & $\mathrm{X}_{9}$ & $\mathrm{X}_{10}$ & $\mathrm{X}_{11}$ \\
\hline $\mathrm{I}$ & 75 & 90 & 35 & 80 & 60 & 45 & 70 & 90 & 30 & 95 & 50 \\
\hline $\mathrm{II}$ & 33 & 90 & 55 & 50 & 30 & 7 & 95 & 80 & 80 & 65 & 95 \\
\hline $\mathrm{III}$ & 10 & 30 & 87 & 90 & 95 & 30 & 60 & 75 & 55 & 37 & 75 \\
\hline $\mathrm{IV}$ & 50 & 45 & 60 & 47 & 20 & 20 & 85 & 80 & 95 & 45 & 85 \\
\hline $\mathrm{V}$ & 25 & 15 & 30 & 90 & 95 & 5 & 35 & 30 & 20 & 35 & 50 \\
\hline
\end{tabular}

Table 8. Modeling results

\begin{tabular}{|c|l|l|l|l|l|l|l|}
\hline & $\mathrm{Y}_{1}$ & $\mathrm{Y}_{2}$ & $\mathrm{Y}_{3}$ & $\mathrm{Y}_{4}$ & $\mathrm{Y}_{5}$ & $\mathrm{Y}_{6}$ & $\mathrm{Y}$ \\
\hline $\mathrm{I}$ & 58 & 94 & 85 & 33 & 61 & 83 & 57 \\
\hline II & 55 & 15 & 94 & 96 & 59 & 94 & 71 \\
\hline III & 33 & 92 & 68 & 66 & 85 & 82 & 54 \\
\hline IV & 53 & 6 & 93 & 91 & 50 & 93 & 69 \\
\hline V & 4 & 93 & 17 & 29 & 94 & 61 & 34 \\
\hline
\end{tabular}

As a result of modeling with the help of fuzzy DSS module (Fig. 1) there were received the following values of the quality of transport services:

1) for alternative variant I - 57 balls;

2) for alternative variant II - 71 balls;

3) for alternative variant III - 54 balls.

4) for alternative variant IV -69 balls.

5) for alternative variant $V-34$ balls.

According to the simulation results it is observed, that in the context of estimation of the quality of transport services ( 71 balls) the best variant is the second (II) alternative variant, and the worst one is the fifth $(\mathrm{V})$ alternative variant ( 34 balls).

Also modeling results of the DSS module to estimate the quality of transport services are presented on histogram (Fig. 12).

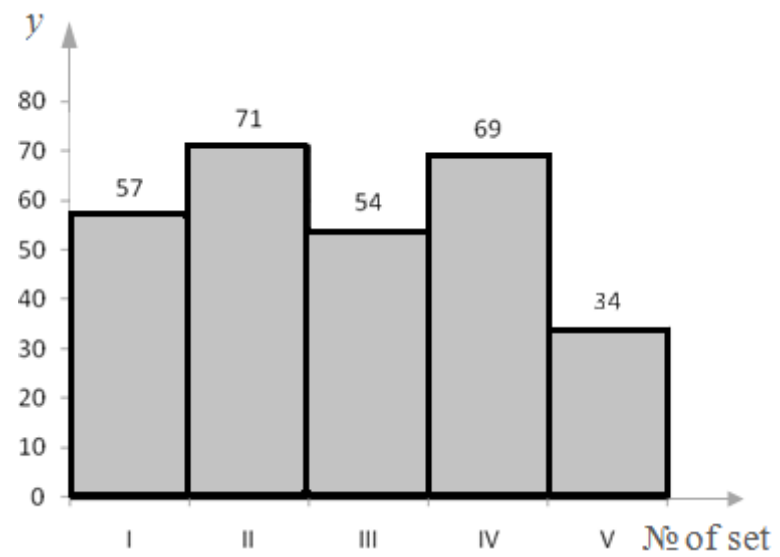

Fig. 12 - Histogram of modeling results

\section{CONCLUSION}

Modular organization of DSS based on fuzzy logic can automatically solve complex problems of transport logistics. It is possible to decide for each task separately.

Theoretic-methodological basis of hierarchicallyorganized structure of intellectual models and algorithms allows to structure and configure developed DSS to solve specific problems of transport logistics.

Method of correction (editing) the rules of fuzzy knowledge bases at different number of input coordinates of the system [23], which developed by the authors, can be used in a modular DSS.

\section{REFERENCES}

[1] L.B. Mirotin, Transport Logistics, Moscow, Examination, 2005, 501 p. (in Russian)

[2] M.P. Denisenko, P.R. Levkovets, L.I. Mikhailova, Organization and Design of Logistics Systems, Kyiv, Center of Educational Literature, 2010, 336 p. (in Ukrainian)

[3] E.V. Krykavskiy, N.I. Chukhrai, Logistics, Kyiv, Condor, 2009, 340 p. (in Ukrainian)

[4] A.M. Gadzhinskiy, Logistics Fundamentals, Moscow, Marketing, 1996, 124 p. (in Russian)

[5] Y.P. Kondratenko, Ie.V. Sidenko, Classification analysis of transport logistics problems and methods of decision-making, 2012 Conference on Modern Information and Innovation Technologies in Transport, Kherson, Ukraine, pp. 172-173. (in Ukrainian)

[6] S. Encheva, Y. Kondratenko, M. Solesvik, S. Tumil, Decision Support Systems in Logistics, 2007 Proc. Intern. Electronic Conf. on Computer Science, IeCCS2007, T.E. Simos and G. Psihoyios (Eds.), American Institute of Physics, CP1060, 2008, pp. 254-256.

[7] Y. Kondratenko, S. Encheva, Ie. Sidenko, Synthesis of fuzzy decision support systems for transport logistics problems, Technical news, Journal of the Ukrainian Engineering Society in Lviv, 1(31), 2(32), 2010, pp. 61-66. (in Ukrainian)

[8] T. Saaty, Decision Making Hierarchy Analysis Method, Moscow, Radio and Communication, 1993, 278 p. (in Russian)

[9] A.A. Bochkarev, Planning and simulation of supply chain, Moscow, Alpha-Press, 2008, 192 p. (in Russian)

[10] O. Kiryukhina, Optimization route delivery in mixed road and rail transportation, Collection of scientific works, Kyiv, Ukraine, 2008, pp. 194-205. (in Ukrainian)

[11] A.P. Kozhin, V. Mezentsev, Mathematical methods in the planning and management of road freight transport, Moscow, Transport, 1994, 304 p. (in Russian)

[12] J. Gil-Aluja, A.M. Gil-Lafuente, A. Klimova, The optimization of the economic segmentation by means of fuzzy algorithms, Journal of Computational Optimization in Economics and Finance, Vol. 1, Iss. 3, pp. 169-186.

[13] A.M. Gil Lafuente, Fuzzy Logic in Financial Analysis. Studies in Fuzziness and Soft Computing, Berlin, Springer, 2005, 223 p. 
[14] A. Taha Hemdi, Introduction to Operations Research, Moscow, Williams, 2007, 912 p.

[15] L.G. Raskin, I.O. Kirichenko, Multi-Index Linear Programming Problem, Moscow, Radio and Communication, 1982, 240 p. (in Russian)

[16] D.B. Yudin, E.G. Holstein, Linear Programming Problem of the Transport Type, Moscow, Science, 1969, 535 p. (in Russian)

[17] Lukinskiy V.S. Models and Methods of the Logistics, St. Petersburg, 2003, 219 p. (in Russian)

[18] Y.P. Kondratenko, S.B. Encheva, E.V. Sidenko, Synthesis of intelligent decision support systems for transport logistic, 2011 Proceeding of the 6th IEEE International Conference on Intelligent Data Acquisition and Advanced Computing Systems: Technology and Applications, IDAACS'2011, Prague, Czech Republic, pp. 642-646.

[19] G.A. Miller, The magic number seven plus or minus two, Psychological Review, 1956, pp. 81-97.

[20] A.P. Rotshtein, Intellectual technologies of identification, Vinnitsa, UNIVERSUM, 1999, 320 p. (in Russian)

[21] L.S. Globa, M.Y. Ternovoy, D.S. Shtogrina, Creating fuzzy knowledge for intelligent control systems, International Journal of Computing, Ternopil, Ukraine, (7) 1 (2008), pp. 70-80. (in Ukrainian)

[22] S.D. Shtovba, The Design of Fuzzy Systems by Means of MatLab, Moscow, Telecom, 2007, 288 p. (in Russian)

[23] Y.P. Kondratenko, Ie.V. Sidenko, Correction of the knowledge database of fuzzy decision support system with variable structure of the input data, Modeling and Simulation, A.M. GilLafuente, V.V. Krasnoproshin (Eds.), Proceedings of the International Conference MS'12, 2012, pp. 56-61.

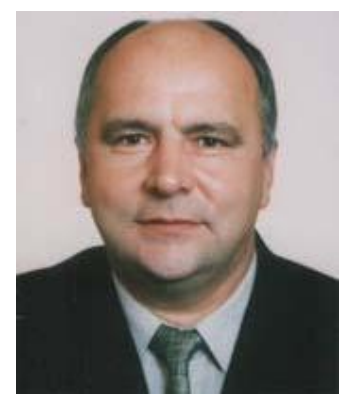

Yuriy Kondratenko, Doctor of Science, Professor, Professor of Intelligent Information Systems on Petro Mohyla Black Sea State University, Ukraine. He is received the Ph.D. (1983) and Dr.Sc. (1994) in Elements and Devices of Computer and Control Systems (EDCCS) from Odessa National Polytechnical University. He received several international grants and schoolarships for conducting research at Institute of Automation of Chongqing University, P.R.China (1988-1989), Ruhr-University Bochum, Germany (2000, 2010), Nazareth College and Cleveland State University, USA (2003).

His research interests include intelligent decision support systems, control systems, fuzzy logic, elements and devices of computing systems.

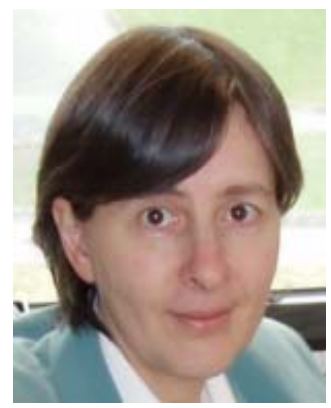

Sylvia Encheva is a full professor of both mathematics and informatics and a director of a R\&D program 'Applied Information Technology' at Stord/Haugesund University College, Haugesund, Norway. She obtained a $P h$. D. in informatics at the University of Bergen, Bergen,

Norway. She has more than 25 years of teaching experience and published over 350 research papers in refereed international journals and conference proceedings.

Her research interests include decision support systems, non-classical logic, computer aided teaching, Web-based assessment and information security.

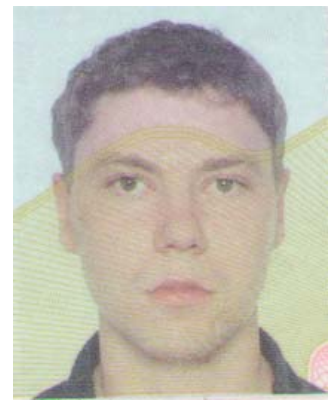

levgen Sidenko, is a $P h D$ student of Petro Mohyla Black Sea State University, Ukraine. $\mathrm{He}$ is specialist in Decision support systems. He has gained several diplomas of junior specialist, bachelor, specialist and master of computer science and diploma of bachelor of enterprise economics.

His research interests include expert systems, fuzzy sets theory and fuzzy logic, intelligent decision support systems, system programming, data mining. 